\title{
Effect of changes in head postures during use of laptops on muscle activity of the neck and trunk
}

\author{
Seulgi Lee ${ }^{a}$, Yeseb Lee ${ }^{a}$, Yijung Chung ${ }^{b, c}$ \\ ${ }^{a}$ Department of Physical Therapy, The Graduate School, Sahmyook University, Seoul, Republic of Korea \\ ${ }^{b}$ Department of Physical Therapy, College of Health and Welfare, Sahmyook University, Seoul, Republic of Korea \\ Institute of Women's Health Physical Therapy, Sahmyook University, Seoul, Republic of Korea
}

Objective: This study tried to examine the muscle activity of the neck and trunk according to head posture changes during use of laptops.

Design: Cross-sectional study.

Methods: This study included nineteen young men and women. All subjects maintained each posture while practice typing on laptops for ten minutes with a 5-minute break between each posture. For the neutral head posture, the subjects practiced typing while pulling their chins down towards the Adam's apple and were able to look at their knees while having their external auditory meatus, acromion, and greater trochanter vertical to the ground. For the natural head posture, they practiced typing while balancing their posture between extension and flexion of the cervical vertebrae by themselves without any guidelines. While a forward head posture was created by having their heads face the front horizontal to the rope hanging from the ceiling, they practiced typing with their external auditory meatus located in the place which was $5 \mathrm{~cm}$ in front of the vertical plane. The subjects used general word process but practiced typing with accuracy and high speed. Muscle activities were randomly measured using surface electromyography according to each postures.

Results: The research result had found that muscle activity with the natural head posture was more significantly reduced than that of the forward head posture in the sternocleidomastoid muscle, upper trapezius, cervical vertebral spinae, and thoracic vertebrae spinae muscles $(p<0.05)$ and that the neutral head posture was more significantly reduced than that of forward head posture in the upper trapezius, cervical vertebral spinae, and thoracic vertebrae spinae muscle activity $(p<0.05)$ with significant increases in lumbar spinae muscle activity $(p<0.05)$. Also, muscle activity with the neutral head posture significantly increased more in the sternocleidomastoid muscle and lumbar spinae than that of the natural posture $(p<0.05)$.

Conclusions: Our study results suggest that in order to prevent musculoskeletal pain, the neutral head posture with use of laptops is effective in reducing load to the shoulders and vitalizing the postural muscles.

Key Words: Computer, Electromyography, Neck muscles, Posture

\section{Introduction}

Straker et al. [1] reported that even small changes in the position of the head can increase the load put onto the musculoskeletal system. With information of the movements of the head and neck being inputted into the muscle spindles, forward head posture is created by lower cervical flexion and upper cervical spine extension with associated rounded shoulders, which is considered as a dysfunctional posture, and Szeto et al. [2] reported that forward posture and rounded shoulders activates the upper trapezius muscle. In addition, forward head posture increases muscle activity of the upper trapezius and cervical erector spinae activity [2], and a slumped position can be observed. If the muscle activity of

Received: 27, February, 2017 Revised: 16 March, 2017 Accepted: 16 March, 2017

Corresponding author: Yijung Chung

Department of Physical Therapy, College of Health and Welfare, Sahmyook University, 815 Hwarang-ro, Nowon-gu, Seoul 01795, Republic of Korea Tel: 82-2-3399-1637 Fax: 82-2-3399-1639 E-mail: yijung36@syu.ac.kr

(c) This is an Open-Access article distributed under the terms of the Creative Commons Attribution Non-Commercial License (http://creativecommons.org/licens es/by-nc/4.0) which permits unrestricted non-commercial use, distribution, and reproduction in any medium, provided the original work is properly cited.

Copyright @ 2017 Korean Academy of Physical Therapy Rehabilitation Science 
the muscles that support the trunk, such as the multifidus, erector spinae, abdominal muscles are reduced, the trunk may lean backwards [3]. Forward head posture leads to insufficient coordinated movements for neck control [4] serves as a high risk to the neck and upper limbs causing neck pain [5]. Weon et al. [6] stated that muscle activity of the upper and lower trapezius are reduced when the head is in a neutral position.

When the head and neck are aligned, proper viewing distance is maintained and there is reduced loading on the neck and shoulder muscles [7]. Hamilton [8] stated that the less amount of head posture being out of range of the spinal alignment, the greater the reduction in tension of the neck muscles.

Since there has been various previous studies that had investigated the effects of changes in head postures during use of computers on muscle activity with many of them focused on the commonly occurring forward head posture while using a computer, our study was focused on similar effects on the shoulder and trunk muscle activity $[9,10]$.

However, three different types of head postures have been investigated for this study, which included the neutral, relaxed, and forward head postures. This study had the subjects maintain the neutral head position by having the external ear canal, acromion, and greater trochanter being vertically aligned, which was similar to the methods used in previous studies.

Therefore, the purpose of this study was to investigate the effects of performing a neutral, relaxed, and forward head posture on muscle activity during the use of laptops.

\section{Methods}

\section{Subjects}

Subjects provided their informed consent after they were presented with the test procedures and conditions and provided. A total of twenty-two young male and female subjects voluntarily agreed to participate in the study. However, after the experiment and observing a video results, three subjects were excluded according based on the selection criteria, resulting in the analysis of muscle activity in nineteen subjects.

Selection criteria of subjects were as follows: first, those with no presence of limitation in joint range of motion [11]; second, those with no musculo-skeletal disorders; third, those who were knowledgeable of laptop use [12]; fourth, no pain during wrist and elbow movement; fifth, those who were right-handed [13]; and sixth, those without any musculoskeletal, neurological, or cardiovascular diseases [6].

After applying the electrodes onto the right side of the sternocleidomastoid, upper trapezius, cervical, thoracic, and lumbar muscles, the maximum voluntary isometric contraction (MVIC) of each muscle was assessed in random order. Subjects were asked to maintain each head posture while typing for 10 minutes and were given a 5-minute rest period between each head posture.

For the neutral head position, subjects practiced typing on a laptop with the head in a vertical state with the external ear canal and acromion [6], while pulling the chin downwards towards the Adam's apple [14], and with the ability to see their knees [15] (Figure 1). For the natural head position, with the visual field parallel to the ground, subjects had to have the ability to maintain self-balance without any instructions or guidance and with the head in the most comfortable position [16] while the subjects practiced typing (Figure 2).

For the forward head posture, with the subjects head facing the forwards towards the horizontal plane in relation to a string hanging down vertically from the ceiling, with the subject's ear canal located $5 \mathrm{~cm}$ forward perpendicular from the vertical line [6], for accurate measurements of this study, a $15 \mathrm{~cm}$ plastic ruler was placed horizontally along the ear

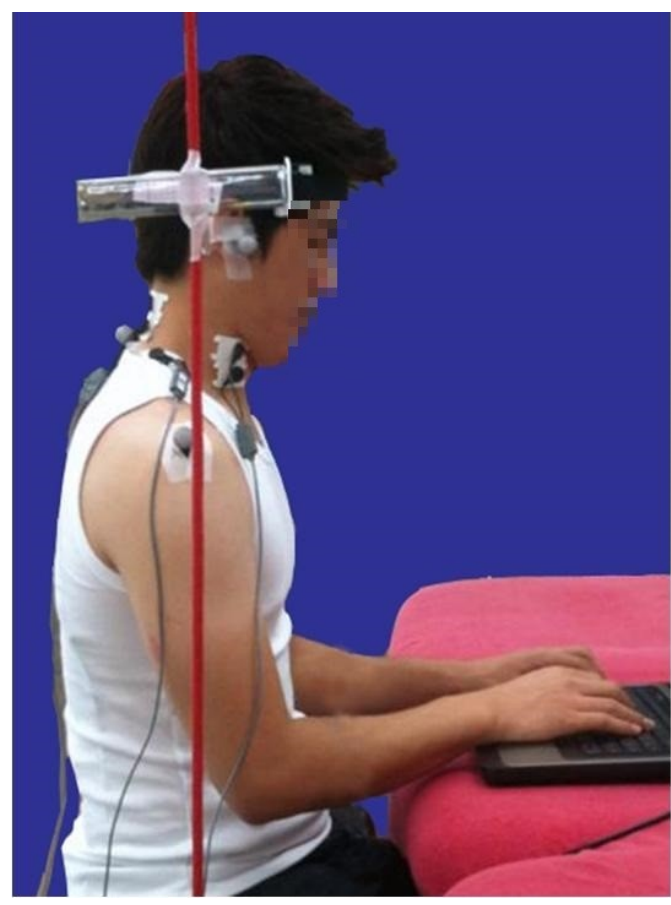

Figure 1. Neutral head position. 


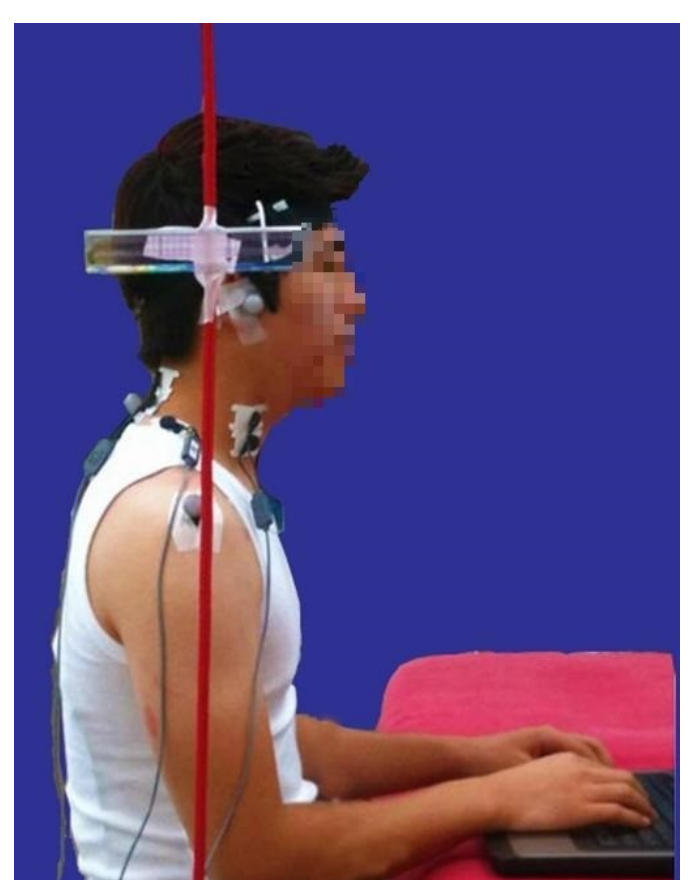

Figure 2. Natural head position.

canal in relation to the vertical line hanging from the ceiling, with a spot marked on the $5 \mathrm{~cm}$ line to accomplish forward head posture (Figure 3). Subjects practiced typing while maintaining the head $5 \mathrm{~cm}$ in front of the marked area on the plastic ruler.

The SONY HDR-CX130 (Sony Corp., Tokyo, Japan) was used to record the subjects practice typing and three subjects who were unable to maintain the required postures were excluded from the study.

Prior to beginning the experiment, subjects were provided with instructions and guidance on how to perform and maintain the neutral, comfortable, and forward head postures by having them practice each position three times in order to maintain the accurate performance of each position.

The study included twenty-two subjects who had satisfied the selection criteria and the MVIC was measured with two evaluators surface electromyography (EMG).

To maintain an accurate posture, the experiment was commenced after the subjects' external ear canal, the 7th cervical spine, and acromion had been marked [6,17]. One experimenter had used the SONY HDR-CX130 to record at the subjects at the beginning and until the end of the experiment in order to confirm for any changes in the tilting of the head [18], and at the conclusion of the experiment, for those who could not maintain the proper head positions from the video replay were excluded from the results.

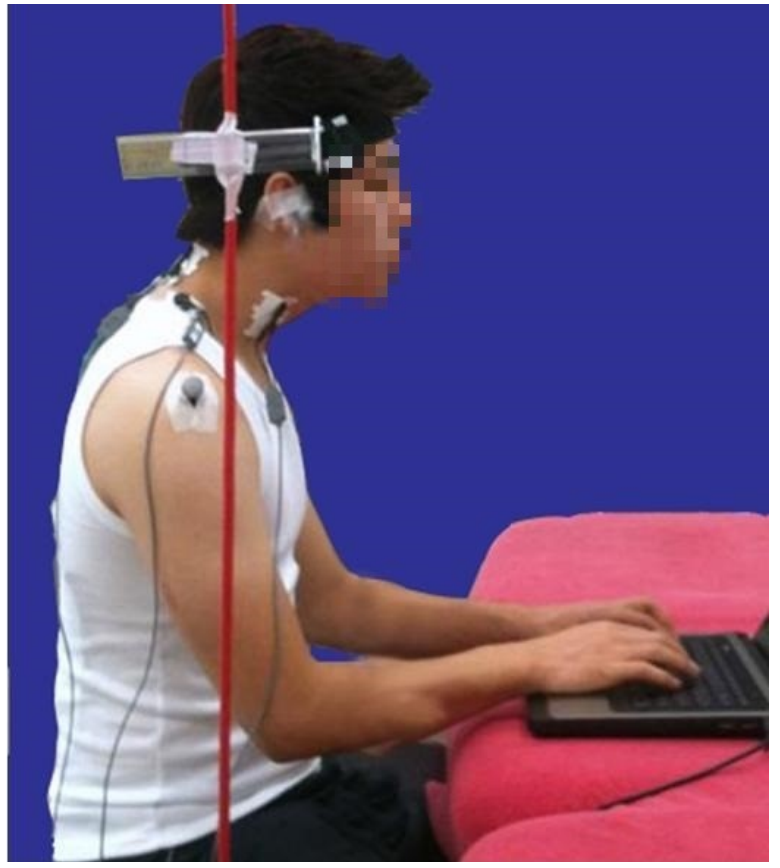

Figure 3. Forward head position.

Subjects sat in a chair without a backrest or armrests with the height of the chair at a level where the subjects' feet touching the ground and with the subject's hips and knees in 90 degrees of flexion [19,20].

Using a height-adjustable desk, the desk was placed at a height that had allowed the subjects to maintain $90^{\circ}$ of elbow flexion [21], and a 15-inch HP 630 laptop PC (HewlettPackard Company, Palo Alto, CA, USA) was used for typing purposes.

The distance of the keyboard from the subjects was placed at the level of the subject's elbows parallel to the desk for typing purposes [22]. This study investigated the effects of maintaining a neutral, comfortable, and forward head posture on muscle activity while typing on a laptop.

All subjects practiced typing with the three different head positions for 10 minutes each [23], and was provided a 5-minute rest period between each head position [24]. Subjects practiced typing as accurately [20] and as fast as possible [25] with sufficient amount of force [26] using a general word processor. In addition, subjects were provided with guidance in order to understand the content of what they were typing [27].

\section{Electromyography}

The EMG equipment (TeleMyo 2400 G2 Telemetry EMG System; Noraxon Inc., Scottsdale, AZ, USA) was used in or- 
der to measure muscle activity. Using the TeleMyo 2400 G2 Telemetry EMG System, electrodes were applied onto the sternocleidomastoid, upper trapezius, cervical, thoracic erector spinae and lumbar erector spinae muscles.

The electrode placement site was $2 \mathrm{~cm}$ distal from the mastoid for the sternocleidomastoid muscle [17], at the center between the 7th cervical vertebra and outer acromion for the upper trapezius, $1 \mathrm{~cm}$ outside of the highest prominence of the 6th cervical vertebra for the cervical erector spinae muscles. $5 \mathrm{~cm}$ outward and parallel to the spine at the level of the 9th thoracic vertebra for the thoracic muscles and a distance of $2 \mathrm{~cm}$ parallel to the spine at the level of the $3 \mathrm{rd}$ lumbar vertebrae for the lumbar muscles. After the data was processed in full-wave rectification, the root mean square value was obtained. Electromyogram signals were normalized into the MVIC values and percentage values were calculated into \%MVIC. The MyoResearch XP Master Edition 1.07 XP software (Noraxon Inc.) was used to measure the EMG signals from the muscles, with the average \%MVIC obtained from three measurements of each subject.

Table 1. General characteristics of subjects

\begin{tabular}{lc}
\hline Characteristic & Subject \\
\hline Gender & \\
Male & 15 \\
Female & 4 \\
Age $(\mathrm{yr})$ & $21.9(2.50)$ \\
Height $(\mathrm{cm})$ & $171.1(9.31)$ \\
Weight $(\mathrm{kg})$ & $63.6(13.88)$ \\
Dominant hand & Right-hand \\
\hline
\end{tabular}

Values are presented as number only or mean (SD).

\section{Statistical analysis}

Statistical analysis, including the mean and standard deviation values, was performed using the SPSS Statistics ver. 12.0 (SPSS Inc., Chicago, IL, USA) program. A normality test was conducted of the general characteristics subjects and variables by the Shapiro-Wilk test and a one-way repeated measures ANOVA was conducted to investigate for the differences in muscle activity according to the neutral, comfortable, and forward head postures. Post-hoc analysis was performed with the least significant difference and the statistical significance level was set at 0.05 .

\section{Results}

\section{General characteristics of subjects}

The general characteristics of subjects are listed as follows. Out of a total of 19 subjects, there were 15 males $(79 \%)$ and 4 females $(21 \%)$ subjects, all who were right-hand dominant. The average age was $21.9 \pm 2.50$ years, average height was $171.1 \pm 9.31 \mathrm{~cm}$, and average weight was $63.6 \pm 13.88 \mathrm{~kg}$ (Table 1).

\section{Comparison of muscle activity according to changes in head posture}

There was a significant decrease in muscle activity of the sternocleidomastoid, upper trapezius, cervical and thoracic muscles with the neutral head posture compared to the forward head posture $(p<0.05)$. There was a significant decrease in muscle activity of the upper trapezius, cervical, and thoracic muscles $(p<0.05)$, but a significant increase in lumbar muscle with the neutral head posture compared to the forward head posture $(p<0.05)$. Also, there was a significant

Table 2. Comparison of muscle activity with changes in head posture

$(\mathrm{N}=19)$

\begin{tabular}{ccccr}
\hline \multirow{2}{*}{ Muscle } & \multicolumn{4}{c}{ Muscle activation } \\
\cline { 2 - 5 } & Neutral head & Natural head & Forward head & $F(p)$ \\
\hline SCM (\%MVIC) & $1.69(1.13)^{\mathrm{a}, \mathrm{b}}$ & $1(0.40)^{\mathrm{a}}$ & $1.2(0.62)$ & $6.308(0.009)$ \\
UT (\%MVIC) & $3.09(1.91)^{\mathrm{a}}$ & $3.28(1.95)^{\mathrm{a}}$ & $5.13(2.76)$ & $12.461(0.000)$ \\
CES (\%MVIC) & $6.09(2.86)^{\mathrm{a}}$ & $5.75(2.10)^{\mathrm{a}}$ & $7.77(2.49)$ & $10.407(0.000)$ \\
TES (\%MVIC) & $7.15(2.57)^{\mathrm{a}}$ & $7.1(2.41)^{\mathrm{a}}$ & $8.76(2.93)$ & $4.140(0.034)$ \\
LES (\%MVIC) & $5.46(2.21)^{\mathrm{a}, \mathrm{b}}$ & $4.03(2.21)$ & $4.01(2.78)$ & $3.478(0.042)$ \\
\hline
\end{tabular}

Values are presented as mean (SD).

SCM: sternocleidomastoid, \%MVIC: percentage of maximum voluntary isometric contraction, UT: upper trapezius, CES: cervical erector spinae, TES: thoracic erector spinae, LES: lumbar erector spinae.

${ }^{a}$ Statistically significant difference compared to forward head posture $(p<0.05)$, ${ }^{b}$ Statistically significant difference when comparing with natural head posture $(p<0.05)$. 
increase in sternocleidomastoid and lumbar spine muscle activity with the neutral head posture compared to the natural head posture $(p<0.05)$ (Table 2).

\section{Discussion}

This study investigated the effects of changes in head postures during use of a laptop on cervical and trunk muscle activity.

Since the weight of the head is about $1 / 7$ of the body and many people have their head and neck postures fixated during prolonged use of computers with repetitive use of the keyboard, excessive load is applied onto to the shoulders, which subsequently causes pain. Cook et al. [21] stated that relaxation of the cervical extensor muscles is important for the correction of a forward head posture. Villanueva et al. [28] reported that head posture has an influence on trunk muscle activity while Andersson et al. [29] stated that elector spinae muscle activity is reduced with the round-back sitting position.

The activation of the erector spine, multifidus, abdominal muscles can lead to correct alignment of the spine can be maintained and reduce postural stress put onto the body that may lead to discomfort [30]. Weon et al. [6] reported decreased upper and lower trapezius muscle activity with a neutral head position. Falla et al. [31] found chronic neck pain could be reduced with the maintenance of an upright body position.

An upright position of the head and neck allows for a proper viewing distance and load reduction of the neck and shoulder muscles [7]. For the prevention of musculoskeletal disorders of the eye during VDT use, it is necessary for the head and neck to be in an upright position [3].

When the head and neck is in an upright position in computer users, an appropriate distance from the screen can be maintained and reduce the load put onto the shoulders [7]. A study by Falla et al. [31] showed that the erector spinae muscle activation is related to the flexion-relaxation phenomenon and was reported to increase the muscle activity of the postural muscles.

The large trunk muscles assists to align the head, neck, and shoulders, thus creating a stabilized posture. Johnston et al. [32] stated that shoulder discomfort was related to upper trapezius muscle activity. Mathiassen [33] reported that neck and shoulder pain in computer users can be reduced with postural correction.

Therefore, this study suggests a neutral head posture for laptop users in order to decrease load onto the neck and shoulders and to maintain proper alignment of the spine by usage of postural muscles.

\section{Conflict of Interest}

The authors declared no potential conflicts of interest with respect to the authorship and/or publication of this article.

\section{References}

1. Straker L, Burgess-Limerick R, Pollock C, Coleman J, Skoss R, Maslen B. Children's posture and muscle activity at different computer display heights and during paper information technology use. Hum Factors 2008;50:49-61.

2. Szeto GP, Straker LM, O'Sullivan PB. A comparison of symptomatic and asymptomatic office workers performing monotonous keyboard work--2: neck and shoulder kinematics. Man Ther 2005;10:281-91.

3. Hanten WP, Lucio RM, Russell JL, Brunt D. Assessment of total head excursion and resting head posture. Arch Phys Med Rehabil 1991;72:877-80.

4. Liao MH, Drury CG. Posture, discomfort and performance in a VDT task. Ergonomics 2000;43:345-59.

5. Szeto GP, Lee R. An ergonomic evaluation comparing desktop, notebook, and subnotebook computers. Arch Phys Med Rehabil 2002;83:527-32.

6. Weon JH, Oh JS, Cynn HS, Kim YW, Kwon OY, Yi CH. Influence of forward head posture on scapular upward rotators during isometric shoulder flexion. J Bodyw Mov Ther 2010;14: 367-74.

7. Saito S, Miyao M, Kondo T, Sakakibara H, Toyoshima H. Ergonomic evaluation of working posture of VDT operation using personal computer with flat panel display. Ind Health 1997; 35:264-70

8. Hamilton N. Source document position as it affects head position and neck muscle tension. Ergonomics 1996;39:593-610.

9. Kang JH, Park RY, Lee SJ, Kim JY, Yoon SR, Jung KI. The effect of the forward head posture on postural balance in long time computer based worker. Ann Rehabil Med 2012;36:98-104.

10. Silva AG, Punt TD, Sharples P, Vilas-Boas JP, Johnson MI. Head posture and neck pain of chronic nontraumatic origin: a comparison between patients and pain-free persons. Arch Phys Med Rehabil 2009;90:669-74.

11. Gold JE, Driban JB, Yingling VR, Komaroff E. Characterization of posture and comfort in laptop users in non-desk settings. Appl Ergon 2012;43:392-9.

12. Pan CS, Schleifer LM. An exploratory study of the relationship between biomechanical factors and right-arm musculoskeletal discomfort and fatigue in a VDT data-entry task. Appl Ergon 1996;27:195-200.

13. Samani A, Fernández-Carnero J, Arendt-Nielsen L, Madeleine P. Interactive effects of acute experimental pain in trapezius and sored wrist extensor on the electromyography of the forearm 
muscles during computer work. Appl Ergon 2011;42:735-40.

14. Turner P. Multidimensional scaling analysis of techniques used by physiotherapists in Southeast Australia: a cross-national replication. Aust J Physiother 2002;48:123-30.

15. Steele CM, Hung D, Sejdić E, Chau T, Fraser S. Variability in execution of the chin-down maneuver by healthy adults. Folia Phoniatr Logop 2011;63:36-42.

16. Solow B, Tallgren A. Natural head position in standing subjects. Acta Odontol Scand 1971;29:591-607.

17. Kim MH, Yi CH, Kwon OY, Cho SH, Yoo WG. Changes in neck muscle electromyography and forward head posture of children when carrying schoolbags. Ergonomics 2008;51:890-901.

18. Turville KL, Psihogios JP, Ulmer TR, Mirka GA. The effects of video display terminal height on the operator: a comparison of the 15 degree and 40 degree recommendations. Appl Ergon 1998;29:239-46.

19. Seghers J, Jochem A, Spaepen A. Posture, muscle activity and muscle fatigue in prolonged VDT work at different screen height settings. Ergonomics 2003;46:714-30.

20. Sommerich CM, Starr H, Smith CA, Shivers C. Effects of notebook computer configuration and task on user biomechanics, productivity, and comfort. Int J Ind Ergon 2002;30:7-31.

21. Cook C, Burgess-Limerick R, Papalia S. The effect of wrist rests and forearm support during keyboard and mouse use. Int J Ind Ergon 2004;33:463-72.

22. Bergqvist U. Visual display terminal work- a perspective on long-term changes and discomforts. Int J Ind Ergon 1995;16: 201-9.

23. Straker L, Pollock C, Burgess-Limerick R, Skoss R, Coleman J. The impact of computer display height and desk design on muscle activity during information technology work by young adults. J Electromyogr Kinesiol 2008;18:606-17.

24. Woods M, Babski-Reeves K. Effects of negatively sloped key- board wedges on risk factors for upper extremity work-related musculoskeletal disorders and user performance. Ergonomics 2005;48:1793-808.

25. Straker L, Jones KJ, Miller J. A comparison of the postures assumed when using laptop computers and desktop computers. Appl Ergon 1997;28:263-8.

26. Kimura M, Sato H, Ochi M, Hosoya S, Sadoyama T. Electromyogram and perceived fatigue changes in the trapezius muscle during typewriting and recovery. Eur J Appl Physiol 2007;100: 89-96.

27. Asundi K, Odell D, Luce A, Dennerlein JT. Changes in posture through the use of simple inclines with notebook computers placed on a standard desk. Appl Ergon 2012;43:400-7.

28. Villanueva MB, Sotoyama M, Jonai H, Takeuchi Y, Saito S. Adjustments of posture and viewing parameters of the eye to changes in the screen height of the visual display terminal. Ergonomics 1996;39:933-45.

29. Andersson BJ, Jonsson B, Ortengren R. Myoelectric activity in individual lumbar erector spinae muscles in sitting. A study with surface and wire electrodes. Scand J Rehabil Med Suppl 1974;3:91-108

30. O'Sullivan SB, Schmitz TJ, Fulk G. Physical rehabilitation. 5th ed. Philadelphia: F.A. Davis Company; 2007.

31. Falla D, Jull G, Russell T, Vicenzino B, Hodges P. Effect of neck exercise on sitting posture in patients with chronic neck pain. Phys Ther 2007;87:408-17.

32. Johnston V, Jull G, Souvlis T, Jimmieson NL. Neck movement and muscle activity characteristics in female office workers with neck pain. Spine (Phila Pa 1976) 2008;33:555-63.

33. Mathiassen SE. The statistical confidence of load estimates based on ramp calibration of upper trapezius EMG. J Electromyogr Kinesiol 1996;6:59-65. 